\title{
Identification of proteins with the CDw75 epitope in human colorectal cancer
}

\author{
ÓSCAR MARIÑO-CRESPO, ALMUDENA FERNÁNDEZ-BRIERA* and EMILIO GIL-MARTÍN* \\ Department of Biochemistry, Genetics and Immunology, Biomedical Research Center (CINBIO, \\ 'Centro Singular de Investigación de Galicia'), University of Vigo, 36310 Vigo, Spain
}

Received November 7, 2016; Accepted July 28, 2017

DOI: $10.3892 / \mathrm{ol} .2017 .7336$

\begin{abstract}
The CDw75 epitope is an $\alpha(2,6)$ sialylated antigen overexpressed in colorectal cancer (CRC), where its expression correlates with the progression of the disease. The CDw75 epitope is located mainly in $\mathrm{N}$-glycoproteins, whose identity remains unknown. The aim of the present study was to identify proteins with the CDw75 epitope as a strategy to deepen the understanding of molecular pathogenesis of CRC and to identify novel biomarkers for this disease. For this purpose, a two-dimensional electrophoresis approach was employed. Protein spots in the gels were matched to the corresponding CDw75 positive spots in the immunoblotted polyvinylidene difluoride membranes, and further identification of the protein species was performed by mass spectrometry. Additionally, one-dimensional western blotting experiments were performed to verify the expression of these candidate proteins in the colorectal tissue and their coincidence in molecular mass with the CDw75-positive bands. The findings of the present study indicate that haptoglobin and the keratins 8 (K8) and 18 (K18) are proteins with the CDw75 epitope in the colorectal
\end{abstract}

Correspondence to: Dr Emilio Gil-Martín or Dr Almudena Fernández-Briera, Department of Biochemistry, Genetics and Immunology, Biomedical Research Center (CINBIO, 'Centro Singular de Investigación de Galicia'), University of Vigo, Campus As Lagoas-Marcosende, 36310 Vigo (Pontevedra), Spain

E-mail: egil@uvigo.es

E-mail: abriera@uvigo.es

*Contributed equally

Abbreviations: CRC, colorectal cancer; 1D, one-dimensional; 2D, two-dimensional; ERp44, endoplasmic reticulum resident protein 44; GRP-78, $78 \mathrm{kDa}$ glucose-regulated protein; Hp, haptoglobin; HSP70-1A, heat shock $70 \mathrm{kDa}$ protein $1 \mathrm{~A}$; K8/K18, keratin 8/18; LRMP, lymphoid-restricted membrane protein; MS, mass spectrometry; RPSA, 40S ribosomal protein SA; ST6Gal I, $\beta$-galactoside $\alpha(2,6)$ sialyltransferase; WB, western blotting; PVDF, polyvinylidene difluoride

Key words: biomarker, CDw75, colorectal cancer, haptoglobin, keratin 8 , keratin 18 tissue from CRC patients and also suggest novel functions and cellular locations for these proteins in the colorectal tissue and in relation to $\mathrm{CRC}$.

\section{Introduction}

The CDw75 epitope, also referred as CD75s (1) or CD75 (2), is a B/T-cell sialylated antigen located at the terminal position of poly-N-acetyl-lactosamine residues (3). The sequence of this glycosylated motif is $\operatorname{Neu} 5 \operatorname{Ac} \alpha(2,6) \mathrm{Gal} \beta(1,4) \mathrm{GlcNAc}$, and it is a part of the glucidic moiety of $\mathrm{N}$ - and O-glycans, particularly of $\mathrm{N}$-glycoproteins (4). The final step of its synthesis is catalyzed by the enzyme $\beta$-galactoside $\alpha(2,6)$ sialyltransferase (ST6Gal I; EC 2.4.99.1) (4).

The CDw75 antigen is a ligand for the leukocyte adhesion receptor cluster of differentiation (CD)22, whose activation leads to the inhibition of intracellular signaling pathways (5). CD22 is located on the B cell membrane and specifically recognizes $\alpha(2,6)$-linked sialic acid $(6,7)$. Given that ST6Gal I knockout mice show low serum B cell and immunoglobulin (Ig)M levels (8), CDw75 must have an important role in B cell proliferation and activation.

Although CDw75 was initially discovered in the B lymphocyte cell membrane, where its expression stops when differentiating into plasma cells (9), several reports have studied the expression of the CDw75 epitope in various epithelial carcinomas, including breast (10), stomach (11) or pancreatic cancer (12).

Colorectal cancer (CRC) is one of the leading types of cancer worldwide, particularly in developed countries. In CRC, ST6Gal I activity affects the adherence (13) and invasion (14) ability of tumor cells. ST6Gal I activity is also associated with the acquisition of the neoplastic phenotype (15), as well as the resistance to irinotecan (16) and Fas-mediated apoptosis (17). Furthermore, in CRC patients, ST6Gal I activity is greater in tumor than in healthy tissue $(18,19)$, particularly in metastatic tumors (20). The CDw75 antigen is expressed in the majority of colorectal tumors, where its expression is augmented with regard to the healthy mucosa $(21,22)$. Additionally, CDw75 expression is particularly high in non-polypoid tumors and advanced or metastatic stages of the disease, although results from clinicopathological studies suggest it could represent a good prognosis marker for 3-year overall survival (23). However, the expression of CDw75 in tumor tissue from 
CRC patients showed no prognostic potential for predicting disease-free survival (23).

Taking into account all the knowledge here presented that link the expression of the CDw75 antigen to CRC development, the authors considered that some of the glycoproteins that bear this epitope could be implicated in the molecular pathogenesis and progression of the disease and therefore, might be used as biomarkers or even as therapeutic targets for this neoplasia. Therefore, the aim of the present study was to identify proteins with the CDw75 epitope in human colorectal tissue.

\section{Materials and methods}

Patients, tissue specimens and cell lines. Colorectal tissue specimens from $26 \mathrm{CRC}$ patients, who underwent surgery at the University Hospital Complex of Ourense (CHUO, Ourense, Spain) between April 2003 and October 2010 were included in the present study. The 26 patients were employed in the following way: 9 patients for the identification of proteins with the CDw75 epitope (mean age 71.9 \pm 5.2 years; age range, $65-78$ years) and 23 patients for the verification of these proteins (mean age $74.8 \pm 9.1$ years; age range, 57-91 years). A total of 6 patients were used in both assays. Apart from the tumor specimens, paired healthy tissues, resected $\geq 10 \mathrm{~cm}$ away from the primary carcinoma, were also employed. Samples were obtained during surgical resection of the tumors and were immediately stored at $-80^{\circ} \mathrm{C}$ until use. The present study received the approval from the Ethical Committee of Clinical Research of Galicia (Health Department, Xunta de Galicia, Spain), and clinical information of patients was treated anonymously. All procedures performed in studies involving human participants were in accordance with the ethical standards of the institutional and/or national research committee and with the 1964 Helsinki declaration and its later amendments or comparable ethical standards.

For the purpose of this work, two CRC cell lines were also employed: Caco-2 [American Type Culture Collection (ATCC), HTB-37] and HT-29 (ATCC, HTB-38), who were donated by Dr. Craig Murdoch (School of Clinical Dentistry, University of Sheffield, UK). Caco-2 cells were cultured in Dulbecco's modified Eagle's medium (Thermo Fisher Scientific, Inc., Waltham, MA, USA) supplemented with $10 \%$ fetal bovine serum (Sigma-Aldrich; Merck KGaA, Darmstadt, Germany) and $1 \%$ penicillin/streptomycin (Sigma-Aldrich; Merck KGaA), whereas HT-29 cells were grown in McCoy's 5A medium (Sigma-Aldrich; Merck KGaA) supplemented with $10 \%$ fetal bovine serum, $1 \%$ penicillin/streptomycin and $2 \mathrm{mM}$ L-glutamine (Sigma-Aldrich; Merck KGaA). The two cell lines were maintained at $37^{\circ} \mathrm{C}$ and $5 \% \mathrm{CO}_{2}$, and harvested when the cells reached confluence. Caco- 2 cells were also left for 15 days following confluence to spontaneously differentiate, and the medium was changed daily.

Sample processing. Tissue specimens were subjected to a modified version of a previously published protocol (24), with the goal of obtaining subcellular fractions enriched in membrane-associated proteins or in cytosolic species. All procedures were performed on ice bath or alternatively in thermostatic centrifuges. Briefly, the biopsies were mechanically homogenized in $0.01 \mathrm{M}$ Tris- $\mathrm{HCl}$ buffer ( $\mathrm{pH} 7.4$ ) with $0.25 \mathrm{M}$ sucrose and a protease inhibitor cocktail (Complete Mini;
Roche Diagnostics, Basel, Switzerland). Non-homogenized material was removed by centrifugation at $750 \mathrm{x}$ g for $10 \mathrm{~min}$ at $4^{\circ} \mathrm{C}$. The resulting supernatant was subsequently centrifuged at $33,000 \mathrm{x}$ g for $60 \mathrm{~min}$ at $4^{\circ} \mathrm{C}$. In this way, the total cellular membranes were pelleted, and the supernatant contained the crude cytosolic fraction. The two fractions were further centrifuged at $145,000 \mathrm{x}$ g for $45 \mathrm{~min}$ at $4^{\circ} \mathrm{C}$ to eliminate the sucrose. Lastly, final pellets were resuspended in $0.01 \mathrm{M}$ Tris- $\mathrm{HCl}$ buffer ( $\mathrm{pH} 7.4)$ and kept at $-20^{\circ} \mathrm{C}$.

Caco-2 and HT-29 cell lysates were obtained from $75 \mathrm{~cm}^{2}$ flasks at confluence in $500 \mu \mathrm{l}$ RIPA buffer $(0.1 \%$ SDS, $150 \mathrm{mM} \mathrm{NaCl}, 50 \mathrm{mM}$ Tris-HCl (pH 8.5), 0.5\% deoxycholic acid, $1 \%$ NP-40, $2 \mathrm{mM} \mathrm{Na}_{3} \mathrm{VO}_{4}$ and $4 \mathrm{mM} \mathrm{NaF}$ ) supplemented with a protease inhibitor cocktail (Complete Mini; Roche Diagnostics). The resultant cell-free homogenate was incubated on ice for $15 \mathrm{~min}$ and centrifuged at 9,600 $\mathrm{x}$ g for $10 \mathrm{~min}$ at $4^{\circ} \mathrm{C}$ to discard cell debris. The subsequent supernatant was preserved at $-20^{\circ} \mathrm{C}$. Finally, total protein measurements were performed using the bicinchoninic acid method, following manufacturer's instructions (Sigma-Aldrich; Merck KGaA).

Two-dimensional western blotting. Given that the CDw75 epitope has been described as a membrane-associated antigen and alterations in the cell membrane glycoconjugates is a well-known tumor characteristic (25), only the preparations enriched in membrane-associated proteins were used for two-dimensional (2D) western blotting. Prior to 2D electrophoresis, the samples were subjected to a desalting step by ultrafiltration through $10 \mathrm{kDa}$ molecular weight cut-off Amicon $^{\odot}$ Ultra-4 centrifugal filter units (Sigma-Aldrich; Merck KGaA), three times at $2,700 \mathrm{x}$ g for $30 \mathrm{~min}$ at $4^{\circ} \mathrm{C}$. The final retentate $(\sim 25 \mu \mathrm{l})$ was resuspended in a solubilization buffer composed of $7 \mathrm{M}$ urea, $2 \mathrm{M}$ thiourea and 4\% 3-[(3-cholamidopropyl)dimethylammonio]-1-propanesulfonate hydrate (CHAPS) to a final volume of $300 \mu \mathrm{l}$. The protein concentration of the resulting solution was calculated by a modified Bradford assay as previously described (26).

Each experiment consisted of two 2D separations performed at the same time. One gel was involved protein identification by mass spectrometry (MS), whereas the other was used for CDw75 immunodetection by western blotting (WB). In the first dimension, proteins (100 for MS gels or $30 \mu \mathrm{g}$ for WB gels) were subjected to isoelectric focusing ( $\mathrm{pH}$, 4.7-5.9) using ReadyStrip ${ }^{\mathrm{TM}}$ IPG strips (Bio-Rad Laboratories, Inc., Hercules, CA, USA). Afterwards, the strips were washed consecutively in a solution composed of $6 \mathrm{M}$ urea, $50 \mathrm{mM}$ Tris ( $\mathrm{pH} 8.8$ ), $2 \%$ SDS and $30 \%$ glycerol and supplemented with $1 \%$ dithiothreitol or $2.5 \%$ iodoacetamide for protein reduction or alkylation. The second dimension consisted of a denaturing separation in 10\% SDS-PAGE gels.

Following 2D electrophoresis, the proteins were transferred for $80 \mathrm{~min}$ at $120 \mathrm{~V}$ to polyvinylidene difluoride (PVDF) membranes (Hybond P 0.45; GE Healthcare, Chicago, IL, USA). The membranes were blocked with 5\% non-fat dry milk in PBS for $1 \mathrm{~h}$ at room temperature and then incubated with an anti-CDw75 monoclonal antibody (1:1,250; catalog no. MA5-11900; Thermo Fisher Scientific, Inc., Waltham, MA, USA) overnight at $4^{\circ} \mathrm{C}$.

Following several washes with PBS, the membranes were incubated with an alkaline phosphatase-conjugated secondary 
antibody for $1 \mathrm{~h}$ (1:15,000, catalog no. A9688; Sigma-Aldrich; Merck KGaA). Finally, the membranes were incubated in darkness with 5-bromo-4-chloro-3-indolyl-phosphate/nitro blue tetrazolium (Sigma-Aldrich; Merck KGaA) until CDw75 spots appeared. All incubations were performed at room temperature.

One-dimensional western blotting. A standard one-dimensional (1D) WB workflow was also employed. Briefly, $20 \mu \mathrm{g}$ protein from crude cytosol- and membranes-enriched fractions were separated in 10\% SDS-PAGE gels, transferred to PVDF membranes, blocked with $5 \%$ non-fat dry milk in PBS for $1 \mathrm{~h}$ at room temperature and probed for several antigens/proteins with monoclonal antibodies: Anti-CDw75 (the same as aforementioned), anti-Hp (1:500; catalog no. ab13429, Abcam, Cambridge, UK), anti-K8 (1:1,250, catalog no. sc-8020, Santa Cruz Biotechnology, Inc., Dallas, TX, USA) and anti-K18 (1:1,250, catalog no. sc-51582, Santa Cruz Biotechnology, Inc.). The membranes were incubated with the primary antibodies for $1 \mathrm{~h}$. After several washes with PBS, CDw75-labelled membranes were incubated with the same secondary antibody used in 2D WB, whereas Hp, K8 and K18 membranes were incubated with a goat anti-mouse IgG horseradish peroxidase-conjugated antibody for $1 \mathrm{~h}(1: 15,000$, catalog no. ab97040; Abcam). All antibody incubations were performed at room temperature.

The development of the membranes was either chromogenic (for CDw75 detection) or chemiluminescent (for detection of $\mathrm{Hp}$, K8 and K18). CDw75-labelled membranes were handled as aforementioned, whereas $\mathrm{Hp}, \mathrm{K} 8$ and K18 membranes were incubated with chemiluminescent reagents according to manufacturer's instructions (Clarity ${ }^{\mathrm{TM}}$ Western ECL Substrate, Bio-Rad Laboratories, Inc.), and visualized using a ChemiDoc ${ }^{\mathrm{TM}}$ XRS+system (Bio-Rad Laboratories, Inc.). With the aim to reuse the membranes for the detection of other epitopes, in some occasions the membranes were stripped with a solution ( $\mathrm{pH} 2.2$ ) of $200 \mathrm{mM}$ glycine, $0.1 \%$ SDS and $1 \%$ Tween-20 (twice for $10 \mathrm{~min}$ ).

Silver staining, spot selection and protein identification. 2D gels were silver-stained for spot visualization. For that purpose, the gels were fixed overnight in $40 \%$ ethanol and $10 \%$ acetic acid, sensitized in $30 \%$ ethanol, $6.8 \%$ sodium acetate and $0.3 \%$ sodium thiosulfate for $30 \mathrm{~min}$, impregnated in $0.1 \%$ silver nitrate for $20 \mathrm{~min}$, developed with $3 \%$ sodium carbonate and $0.01 \%$ formaldehyde, and stopped in $1.5 \%$ EDTA for $10 \mathrm{~min}$.

Spots containing CDw75-carrying proteins were selected after the matching of the paired gel and membrane images with the assistance of the 2D-gel imaging and analysis PDQuest software (version 7.4.0; Bio-Rad Laboratories, Inc.). The selected spots were sent for MS analysis to the Scientific and Technical Support Centre for Research (CACTI, University of Vigo, Spain).

Proteins were digested in gel with trypsin using a DP Chemical 96 kit (Bruker Corporation, Billerica, MA, USA). Tryptic peptides were analyzed by matrix-assisted laser desorption/ionization-time of flight tandem mass spectrometry (MALDI-TOF/TOF) with an Autoflex III smartbeam (Bruker Corporation). The data was acquired and analyzed automatically using the flexControl 3.0 and flexAnalysis 3.0 software
(Bruker Corporation), respectively. When possible, the major peaks obtained by MALDI-TOF were selected to be further characterized by TOF/TOF analyses. $\mathrm{m} / \mathrm{z}$ data were submitted for database searching against SwissProt 56.6 (http://web. expasy.org/docs/swiss-prot_guideline.html). Search parameters were set as follows: Taxonomy Homo sapiens, enzyme trypsin, allowance of one missed cleavage site, carbamidomethyl of cystein as fixed modification, oxidation of methionine as variable modification, monoisotopic mass values, $100 \mathrm{ppm}$ of mass tolerance for precursor ions, 0.5 Da mass tolerance for fragment ions and protein mass unrestricted.

For greater certainty, protein identifications were carefully studied to select the candidates that, in addition to being statistically significant, i) had similar molecular masses and isoelectric points compared with those of the spots in which they were identified; ii) were expressed in colorectal tissue and iii) were known to be glycoproteins. For this step, the following databases were used: UniProt (http://www.uniprot .org/), Human Protein Reference Database (http://www.hprd .org/query), The Human Protein Atlas (http://www.proteinatlas.org/), Ensembl (http://www.ensembl.org/index.html) and SWISS-2DPAGE (http://www.expasy.org/swiss-2dpage?de).

Statistical analysis. All statistical analyses were performed with the IBM SPSS Statistics software (version, 19.0; IBM Corp., Armonk, NY, USA). In order to compare the expression of the assayed proteins among different tissues and subcellular fractions, the Wilcoxon signed-rank test was employed. To find out whether the expression of the proteins was correlated with the expression of the CDw75 antigen, the Pearson's correlation test was used. $\mathrm{P}<0.05$ was considered to indicate a statistically significant difference.

\section{Results}

Identification of glycoproteins that contain the CDw75 sequence. Prior to the 2D protein separation, $9 \mathrm{CRC}$ patients were screened by $1 \mathrm{D} \mathrm{WB}$ in order to select samples with marked CDw75 expression and/or notable differences between healthy and tumor tissue (Fig. 1). According to these criteria, 5 patients (patients 1, 4, 5, 7 and 8) were selected for the separation, selection and identification of proteins with the CDw75 epitope. In 2D CDw75 immunoblots, the epitope appeared as 4- 8 positive spots located on a narrow area of the membranes, between 44-50 kDa in molecular mass and 4.9-5.1 of isoelectric point (Fig. 2). Differences in CDw75 spot pattern between healthy and tumor tissue or association with tumor stage were not detected. A summary of the MS findings is shown in Table I.

Following careful consideration of the candidates included in Table I, only three proteins (Hp, K8 and K18) were found to fulfill all the requirements established for selection: Correspondence in molecular mass and isoelectric point with CDw75-positive spots, as well as known colorectal expression and glycoprotein structure.

Verification of proteins with the CDw75 epitope. Several 1D WB assays were performed to check whether the CDw75 expression pattern was coincident with the bands generated by $\mathrm{Hp}, \mathrm{K} 8$ and K18 immunostaining. For this purpose, detection of 

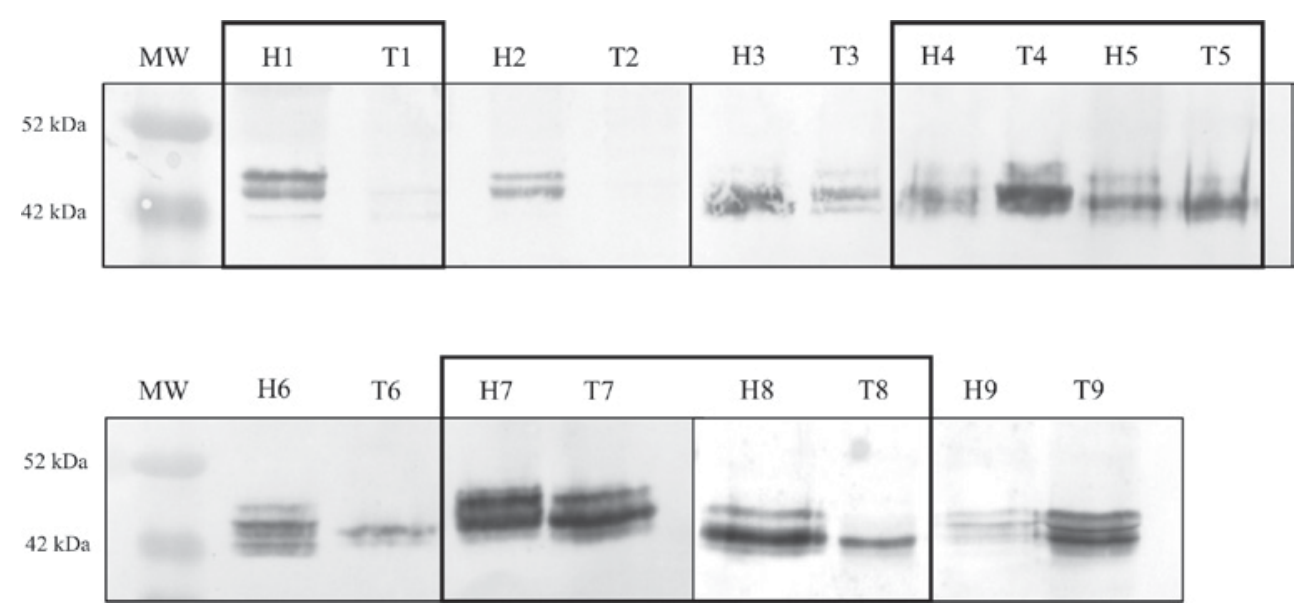

Figure 1. Immunoblots for CDw75 expression in membrane-enriched protein fraction from healthy and tumor specimens from patients with colorectal cancer $(n=9)$. Highlighted samples were selected for two-dimensional separation and subsequent protein identification by mass spectrometry. Both images are composites of two different sets of patients that were analyzed separately (boundaries are marked by a vertical line). MW, molecular mass marker; H, healthy tissue; T, tumor tissue.

$\mathbf{A}$

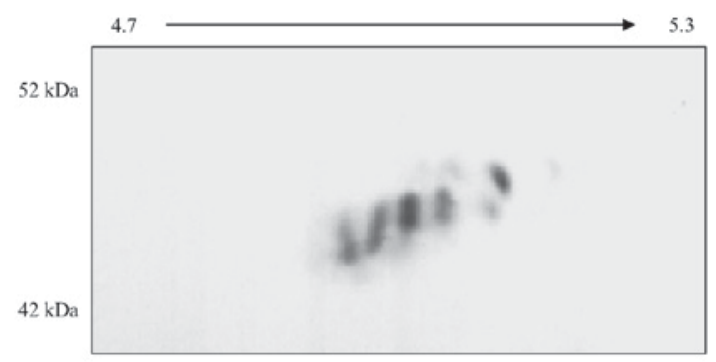

B

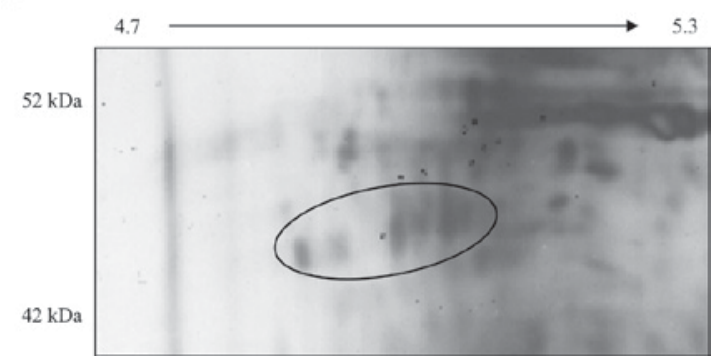

Figure 2. Representative two-dimensional pattern of CDw75 expression in (A) one of the analyzed colorectal specimens and (B) the corresponding silver-stained gel. The sample is a total membrane-enriched fraction from the tumoral specimen of patient 5. The $\mathrm{x}$-axis indicates the isoelectric point gradient, whereas the y-axis represents the molecular mass of the standards. The circle marks the protein spots that were selected for identification by mass spectrometry. MW, molecular mass marker.

each candidate protein in membrane- and cytoplasmic-enriched fractions from $23 \mathrm{CRC}$ patients was performed. The membranes were then stripped and assayed for the presence of CDw75. The exact number of specimens employed for each assay were as follows: 5 for Hp, 18 for K8 and 17 for K18. The majority of the specimens were analyzed for more than one protein.

The Hp signal appeared as a single and blurred 40-45 kDa band, whereas the expression of CDw75 obtained in the same patients was heterogeneous, ranging from null to four intense 42-47 kDa bands (Fig. 3A). The expression of Hp and
CDw75 was more abundant in the cytosol compared with the membrane fraction $(\mathrm{P}=0.043$ for $\mathrm{Hp}$ in healthy and tumor tissue; not significant for CDw75). The expression of both molecules was significantly correlated in the membrane fraction from healthy tissue $(\mathrm{n}=5, \mathrm{P}=0.018)$.

The expression of K8 was detected as two or three bands, ranging from 42 to $47 \mathrm{kDa}$, and showed a considerable heterogeneity. The CDw75 signal in the same patients was also diverse, with up to four bands in the range of 42-46 kDa (Fig. 3B). The expression of K8 and CDw75 was more intense in the cytoplasmic compared with in the membrane fraction (only in healthy tissue, $\mathrm{P}=0.043$ for $\mathrm{K} 8$ and $\mathrm{P}=0.042$ for $\mathrm{CDw} 75$ ). The expression level of both molecules was correlated in the cytoplasmic fractions from healthy $(\mathrm{n}=18, \mathrm{P}=0.002)$ and tumor $(\mathrm{P}=0.050)$ tissue.

The expression of K18 also displayed a substantial heterogeneity, with zero to three bands ranging from 43 to $47 \mathrm{kDa}$ (Fig. 3C). A similar pattern was observed for CDw75, with up to four bands with $42-46 \mathrm{kDa}$ that exhibited a great variability depending on the patient. The expression of K18 and CDw75 was more intense in the cytoplasmic compared with in the membrane fraction (only in healthy tissue, $\mathrm{P}=0.043$ for $\mathrm{K} 18$ and $\mathrm{P}=0.042$ for $\mathrm{CDw} 75)$. The expression level of both molecules was significantly correlated in the cytoplasmic fraction from healthy tissue $(\mathrm{n}=17, \mathrm{P}=0.019)$.

To complete the study of colorectal tissue from CRC patients, Caco-2 and HT-29 cell lysates were also screened with the same experimental strategy (Fig. 4). In the WB assay performed, the CDw75 epitope appeared as a $46 \mathrm{kDa}$ band, accompanied by a $48 \mathrm{kDa}$ band in differentiated Caco- 2 cells. Hp was not detected in any of the two replicates performed, whereas $\mathrm{K} 8$ and $\mathrm{K} 18$ were detected as a single $46 \mathrm{kDa}$ band in HT-29 cells and in both differentiation states of Caco- 2 cells.

\section{Discussion}

CDw75 is an $\alpha(2,6)$ sialylated antigen abnormally expressed in different epithelial tumors. Although this epitope is more abundant in the tumor tissue from CRC patients and its expression levels seem to correlate with the development of 
Table I. Summary of the results from the 2-D electrophoresis separation and mass spectrometry identification of CDw75-carrying proteins in colorectal tissue from colorectal cancer patients.

\begin{tabular}{|c|c|c|c|c|c|}
\hline Sample & Tissue & Protein & UniProt accession number & Spots MS & Spots MS/MS \\
\hline \multirow[t]{8}{*}{1} & \multirow[t]{8}{*}{ Healthy } & Keratin 1 & P04264 & 1 & - \\
\hline & & Keratin 8 & P05787 & 4 & 1 \\
\hline & & Keratin 18 & P05783 & 12 & - \\
\hline & & Keratin 19 & P08727 & 1 & - \\
\hline & & Haptoglobin & P00738 & 4 & 2 \\
\hline & & Seroalbumin & P02768 & 1 & - \\
\hline & & Actin & & 3 & 3 \\
\hline & & ATP synthase subunit $\beta$ & P06576 & 1 & - \\
\hline \multirow[t]{6}{*}{4} & \multirow[t]{2}{*}{ Healthy } & Keratin 8 & P05787 & 1 & - \\
\hline & & Keratin 18 & P05783 & 2 & - \\
\hline & \multirow[t]{4}{*}{ Tumor } & Actin & - & 1 & 4 \\
\hline & & Seroalbumin & P02768 & 1 & - \\
\hline & & $\begin{array}{l}\text { Cytochrome b-c } 1 \text { complex } \\
\text { subunit } 1, \text { mitochondrial }\end{array}$ & P31930 & - & 1 \\
\hline & & Keratin 18 & P05783 & 1 & 1 \\
\hline \multirow[t]{4}{*}{5} & Healthy & Keratin 8 & P05787 & 2 & - \\
\hline & \multirow[t]{3}{*}{ Tumor } & Keratin 8 & P05787 & 1 & - \\
\hline & & Keratin 19 & P08727 & 3 & 1 \\
\hline & & LRMP & Q12912 & - & 1 \\
\hline \multirow[t]{6}{*}{7} & \multirow[t]{4}{*}{ Healthy } & Keratin 18 & P05783 & 2 & - \\
\hline & & Keratin 19 & P08727 & 2 & - \\
\hline & & RPSA & P08865 & 1 & 1 \\
\hline & & GRP-78 & P11021 & 1 & - \\
\hline & \multirow[t]{2}{*}{ Tumor } & RPSA & P08865 & 2 & 2 \\
\hline & & Keratin 8 & P05787 & - & 1 \\
\hline \multirow[t]{6}{*}{8} & \multirow[t]{3}{*}{ Healthy } & Keratin 1 & P04264 & 2 & - \\
\hline & & Keratin 9 & P35527 & 1 & - \\
\hline & & HSP70-1A & P0DMV8 & 1 & - \\
\hline & \multirow[t]{3}{*}{ Tumor } & Actin & - & 1 & 1 \\
\hline & & ERp44 & Q9BS26 & 1 & 1 \\
\hline & & Haptoglobin & P00738 & - & 1 \\
\hline
\end{tabular}

Data from sample 1 are the sum of identified spots from three assays. Spots MS, number of spots identified by simple mass spectrometry; Spots MS/MS, number of spots identified by tandem mass spectrometry; LRMP, lymphoid-restricted membrane protein; RPSA, 40S ribosomal protein SA; GRP-78, $78 \mathrm{kDa}$ glucose-regulated protein; HSP70-1A, heat shock $70 \mathrm{kDa}$ protein 1A; ERp44, endoplasmic reticulum resident protein 44 .

the neoplasia, the fact that most colorectal tumors express the molecule implies that CDw75 expression has a poor prognostic value (23). Additionally, it is unknown if the greater expression of the epitope observed in tumor tissue is a genuine molecular characteristic of CRC or just an epiphenomenon accompanying the malignization of the colorectal mucosa and, therefore, a poor discriminative marker. If the former assumption is true, the identification of overexpressed proteins with CDw75 would contribute to the clarification of the pathogenesis of CRC. Consequently, the objective of the present study was to identify the protein species that have the CDw75 motif in human CRC.

Several different candidates were initially identified by MS (Table I) in spots that were selected by its coincidence in molecular mass and isoelectric point with CDw75-positive spots in 2D WB. However, the present study considered that a spatial coincidence was insufficient to state conclusively that these proteins have the CDw75 epitope. Therefore, each of these proteins was searched in the aforementioned databases and thus discarded or accepted as potential CDw75 bearers in CRC.

Keratins 1 and 9 are characteristically expressed in the skin epithelium. Thus, the presence of these proteins in samples other than the skin is usually regarded as a sign of experimental contamination (27). Likewise, the detection of seroalbumin is most likely due to vascular infiltration of the tissue specimens.

Keratin 19, actins, lymphoid-restricted membrane protein (LRMP), 40S ribosomal protein SA (RPSA), $78 \mathrm{kDa}$ 
A

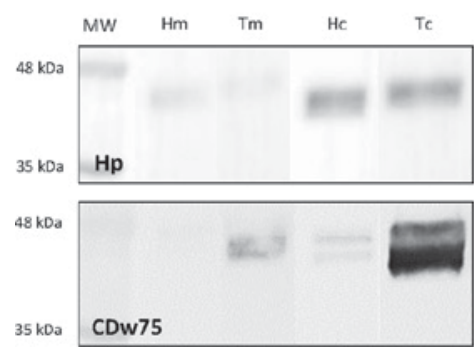

B

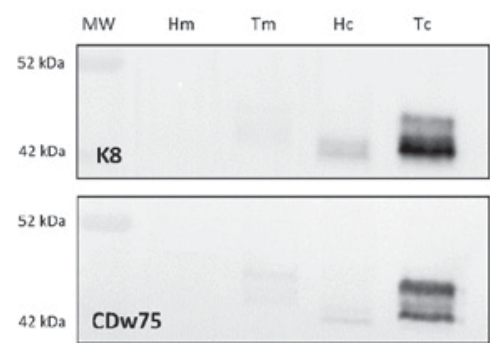

C

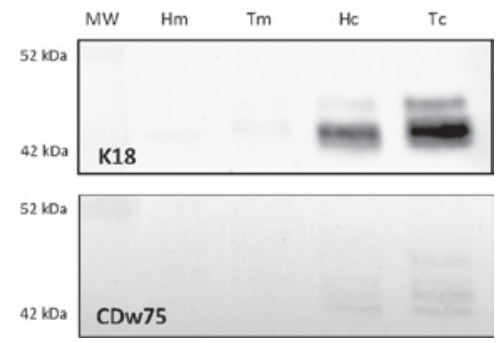

Figure 3. Representative immunoblot images for the expression of (A) haptoglobin, (B) keratin 8 and (C) keratin 18 in crude cytosolic- and total membranes-enriched fractions and comparison with their corresponding immunoblots for the expression of CDw75 (lower panels). A total of 23 colorectal tissue specimens ( 5 for haptoglobin, 18 for keratin 8 and 17 for keratin 18) were analyzed in this assay, of which only 3 are portrayed in this figure. MW, molecular mass marker; Hc, cytoplasmic fraction from healthy tissue; Hm, membrane-enriched fraction from healthy tissue; Tc, cytoplasmic fraction from tumor tissue; Tm, membrane-enriched fraction from tumor tissue; Hp, haptoglobin; K8, keratin 8; K18, keratin 18.
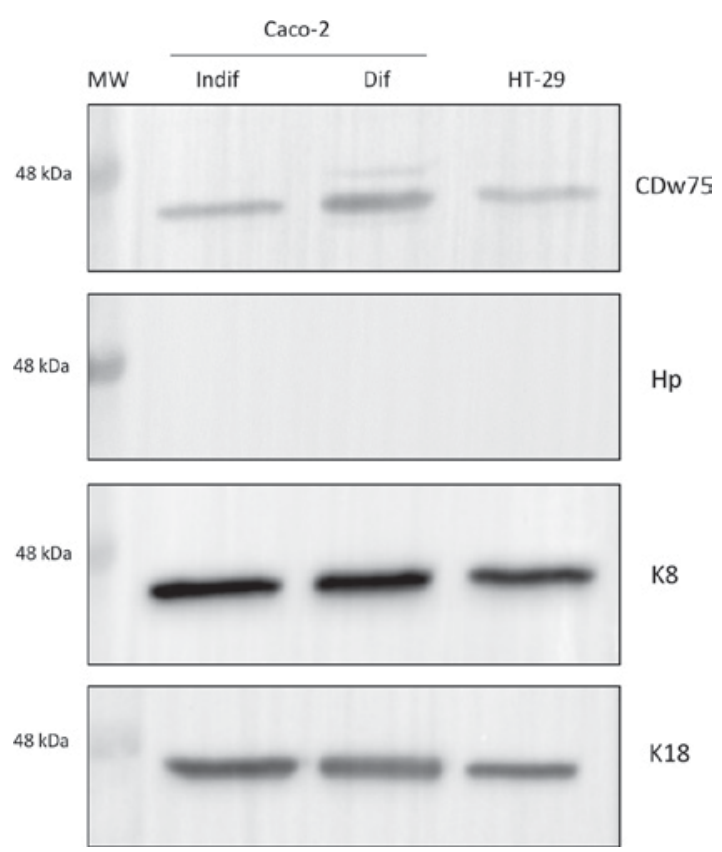

Figure 4. Immunoblots for the expression of CDw75, haptoglobin, keratin 8 and keratin 18 in Caco-2 and HT-29 cell lines. Haptoglobin was assayed twice, whereas the other proteins were tested once. MW, molecular mass marker; Undif, undifferentiated state; Dif, differentiated state; Hp, haptoglobin; K8, keratin 8; K18, keratin 18.

glucose-regulated protein (GRP-78), heat shock $70 \mathrm{kDa}$ protein 1A (HSP70-1A) and endoplasmic reticulum resident protein 44 (ERp44). It was not possible to determine the isoform(s) of actin present. All these proteins are known to be expressed in the colorectal epithelium (28-33), but to date there is no reported evidence of their glycoprotein nature. Therefore, even though some of the proteins have been associated with CRC and other types of neoplasia, including keratin 19 (28), LRMP (29), RPSA (30), GRP-78 (31) and ERp44 (33), these proteins were not further analyzed in subsequent studies.

The ATP synthase subunit $\beta$ (34) and the cytochrome b-c1 complex subunit 1 (35) are mitochondrial proteins associated with ATP production. Consequently, both proteins $(36,37)$ are virtually expressed in all tissues and cells, which probably would make them very unspecific markers. In addition, the two proteins are not known to be glycosylated.
K8 and K18 are well-known single-layered epithelia cytoskeletal proteins (38), which may explain the presence of these proteins in colorectal specimens. Although a total membrane-associated protein fraction was employed, the interaction of $\mathrm{K} 8$ and $\mathrm{K} 18$ with desmosomes and hemidesmosomes (K8 and K18 constitute the intermediate filaments) (39) could explain the presence of these cytoplasmic proteins in membrane preparations. Furthermore, K8 and K18 are known to be glycosylated (40) and were identified in five (K8) and four (K18) of the specimens analyzed in the present study. Therefore, K8 and K18 were considered to be good candidates to have CDw75 in their glycan antennae.

$\mathrm{Hp}$, which was identified in two different tissue specimens in the present study, is an acute-phase protein (a serum polypeptide synthesized by hepatocytes) (41). Nonetheless, the colorectal epithelium expression of $\mathrm{Hp}$ has also been previously reported $(42,43)$. The Hp molecule is composed of two $\alpha$ and two $\beta$ subunits, of which only $\beta$ subunits are glycosylated (44). These reasons led to the selection of $\mathrm{Hp}$ as a putative CDw75-bearing protein.

Although it is likely that $\mathrm{Hp}, \mathrm{K} 8$ and $\mathrm{K} 18$ are not the only proteins that have the CDw75 antigen (in fact, the $48 \mathrm{kDa}$ CDw75 band present in differentiated Caco-2 cells does not coincide with any of the probed proteins by 1D WB), the existing knowledge on their glycosylation status, tissue expression and the association of $\mathrm{Hp}, \mathrm{K} 8$ and $\mathrm{K} 18$ with CRC pathogenesis led us to the continuation of their characterization in the present study. The WB screening revealed that the expression pattern of $\mathrm{Hp}, \mathrm{K} 8$ and $\mathrm{K} 18$ was partially coincident in molecular mass with some of the CDw75-positive bands developed on the same blots.

The unique and wide Hp band observed in WB suggests the presence of one polypeptide, but with high microheterogeneity (possibly due to several glycoforms). Furthermore, a part of the broad band was coincident with CDw75 signals. However, Hp cannot be the only protein that bears this epitope as there are heavier bands present in immunoblots of CDw75 compared with immunoblots of Hp. In previous studies, the sequence Neu5Ac-Gal-GlcNAc has been detected among the multiple carbohydrate determinants that are attached to serum Hp $(45,46)$. Given the complex histological composition of the CRC specimens employed in the present study, and the fact that it was not possible to detect any signal of the protein 
in Caco-2 and HT-29 cell lines by WB, the exact origin of the Hp detected by MS cannot be elucidated, although, as stated previously the protein is known to be expressed in the colorectal epithelium $(42,43)$. In this sense, further evidence is necessary to assess a potential CDw75-glycosylated form of colorectal Hp.

In the present study, the $\mathrm{K} 8 / \mathrm{K} 18$ band pattern in immunoblots appeared almost identical to that of CDw75 in the same CRC specimens, with a similar relative abundance of positive bands in the subcellular fractions compared with the epitope. Regarding $\mathrm{CRC}$ cell lines, the unique $\mathrm{K} 8$ and $\mathrm{K} 18$ bands were also coincident with one of the CDw75-positive bands. These proteins are the main keratin pair in simple epithelia, such as the colorectal epithelium, where K8 and K18 are crucial for tissue homeostasis (47). In addition, there are numerous evidence for abnormalities of K8/K18 expression in CRC (48-52). Despite K8 and $\mathrm{K} 18$ being traditionally described as cytoskeletal proteins, several studies have reported the presence of both keratins on the cell membrane in breast carcinoma (53), K18 in healthy and tumor hepatocytes (54) and $\mathrm{K} 8$ in CRC cells but not in their healthy counterparts (55). Therefore, K8 and K18 might have a cell membrane-associated glucide, such as the CDw75 epitope. In any case, the presence of glycoproteins in the cytoplasm and even in the nucleus is well-documented $(56,57)$. In addition, it is worth mentioning that in the present study the expression of $\mathrm{K} 8$ and CDw75 was associated in healthy and tumor tissues, whereas the expression of K18 and CDw75 were only associated in the healthy tissues. Although these findings call for further research, they also suggest K8/K18 have different glycosylation dynamics in relation to $\mathrm{CRC}$, which could indicate a dissimilar implication of these proteins in the colorectal carcinogenesis. In this sense, it is well known that glycosylation affects protein functionality (58).

In summary, the present study presents several direct and indirect evidence that suggest that $\mathrm{Hp}, \mathrm{K} 8$ and $\mathrm{K} 18$ are CDw75-carrying proteins in colorectal tissue. All of these proteins were identified due to their coincidence in molecular mass and isoelectric point with CDw75-positive spots in 2D WB. Furthermore, these proteins are expressed in the colorectal epithelium and are known to be glycosylated. Since it is unknown whether these proteins normally bear this epitope or it is the result of the malignant transformation of the colorectal epithelium, more studies are necessary to unveil the role of $\mathrm{Hp}$, $\mathrm{K} 8$ and $\mathrm{K} 18$ in the development and progression of CRC.

\section{Acknowledgements}

The present study was funded by the Consellería de Cultura, Educación e Ordenación Universitaria (Xunta de Galicia, Spain) and FEDER (European Union): CINBIO (grant number ED431G/02, 2016-2019), XUGA (grant no. PGIDIT02BTF30101PR) and Research Groups Program (grant no. 2007/00035-0). The funding sources had no involvement in any step of the present study. The authors of the present study wish to thank Dr Craig Murdoch (School of Clinical Dentistry, University of Sheffield, UK), for his donation of the Caco-2 and HT-29 cell lines and for his technical advice in relation to cell culture.

An abstract containing part of this study was presented at the II International Congress on Analytical Proteomics, held in Ourense (Spain) on the 18th-20th July 2011. The abstract was included in the II ICAP 2011-Book of abstracts as contribution no. P14, pp 160.

\section{References}

1. Eichler W: Characteristics of two CD75-related cell-surface expressed antigens of human lymphocytes. Mol Immunol 44: 2047-2055, 2007.

2. Carbone A and Gloghini A: CD75: A B-cell marker which should not be forgotten in lymphocyte predominant Hodgkin lymphoma. Am J Hematol 89: 449, 2014.

3. Harduin-Lepers A, Vallejo-Ruiz V, Krzewinski-Recchi MA Samyn-Petit B, Julien S and Delannoy P: The human sialyltransferase family. Biochimie 83: 727-737, 2001.

4. Dall'Olio F: The sialyl-alpha2,6-lactosaminyl structure: Biosynthesis and functional role. Glycoconj J 17: 669-676, 2000.

5. Nitschke L: The role of CD22 and other inhibitory co-receptors in B-cell activation. Curr Opin Immunol 17: 290-297, 2005.

6. Stamenkovic I, Sgroi D, Aruffo A, Sy MS and Anderson T: The B-lymphocyte adhesion molecule CD22 interacts with leukocyte common antigen CD45RO on T cells and alpha 2-6 sialyltransferase, CD75, on B cells. Cell 66: 1133-1144, 1991.

7. Sgroi D, Varki A, Braesch-Andersen S and Stamenkovic I: CD22, a B cell-specific immunoglobulin superfamily member, is a sialic acid-binding lectin. J Biol Chem 268: 7011-7018, 1993.

8. Hennet T, Chui D, Paulson J and Marth JD: Immune regulation by the ST6Gal sialyltransferase. Proc Natl Acad Sci USA 95: 4504-4509, 1998

9. Dorken B, Moller P, Pezzutto A, Schwartz-Albiez R and Moldenhauer G: B-cell antigens: CDw75. In: Leukocyte Typing IV. White Cell Differentiation Antigens. Knapp W, Dorken B, Gilks WR, Rieber EP, Schmidt RE, Stein $\mathrm{H}$ and von den Borne AEPGK (eds.). Oxford University Press, Oxford, pp109-110, 1989.

10. Reed W, Erikstein BK, Funderud S, Lilleng R, Tvedt K and Nesland JM: CDw75 antigen expression in breast lesions. Path Res Pract 189: 394-398, 1993.

11. Shen L, Li HX, Luo HS, Shen ZX, Tan SY, Guo J and Sun J: CDw75 is a significant histopathological marker for gastric carcinoma. World J Gastroenterol 10: 1682-1685, 2004.

12. DistlerU,Souady J,Hülsewig M,Drmić-HofmanI,Haier J,Denz A, Grützmann R, Pilarsky C, Senninger N, Dreisewerd K, et al: Tumor associated CD75s and CD75s-gangliosides are potential targets for adjuvant therapy in pancreatic cancer. Mol Cancer Ther 7: 2464-2475, 2008.

13. Dall'Olio F, Malagolini N, Di Stefano G, Ciambella M and Serafini-Cessi F: Alpha 2,6 sialylation of N-acetyllactosaminic sequences in human colorectal cancer cell lines. Relationship with non-adherent growth. Int J Cancer 47: 291-297, 1991.

14. Zhu Y, Srivatana U, Ullah A, Gagneja H, Berenson CS and Lance P: Suppression of a sialyltransferase by antisense DNA reduces invasiveness of human colon cancer cells in vitro. Biochim Biophys Acta 1536: 148-160, 2001.

15. Chiricolo M, Malagolini N, Bonfiglioli S and Dall'Olio F: Phenotypic changes induced by expression of beta-galactoside alpha2,6 sialyltransferase I in the human colon cancer cell line SW948. Glycobiology 16: 146-154, 2006.

16. Swindall AF, Londoño-Joshi AI, Schultz MJ, Fineberg N, Buchsbaum DJ and Bellis SL: ST6Gal-I protein expression is upregulated in human epithelial tumors and correlates with stem cell markers in normal tissues and colon cancer cell lines. Cancer Res 73: 2368-2378, 2013.

17. Swindall AF and Bellis SL: Sialylation of the Fas death receptor by ST6Gal-I provides protection against Fas-mediated apoptosis in colon carcinoma cells. J Biol Chem 286: 22982-22990, 2011.

18. Dall'Olio F, Malagolini N, di Stefano G, Minni F, Marrano D and Serafini-Cessi F: Increased CMP-Neu Ac: Gal beta 1,4GlcNAc-R alpha 2,6 sialyltransferase activity in human colorectal cancer tissues. Int J Cancer 44: 434-439, 1989.

19. Vázquez-Martín C, Gil-Martín E and Fernández-Briera A: Elevation of ST6Gal I activity in malignant and transitional tissue in human colorectal cancer. Oncology 69: 436-444, 2005.

20. Gessner P, Riedl S, Quentmaier A and Kemmner W: Enhanced activity of CMP-neuAc:Gal beta 1-4GlcNAc:alpha 2,6-sialyltransferase in metastasizing human colorectal tumor tissue and serum of tumor patients. Cancer Lett 75: 143-149, 1993. 
21. Elpek GO, Gelen T, Karpuzoğlu G, Karpuzoğlu T, Aksoy NH and Keles N: Clinicopathologic evaluation of CDw75 antigen expression in colorectal adenocarcinomas. Pathol Oncol Res 8: $175-182,2002$

22. Costa-Nogueira C, Villar-Portela S, Cuevas E, Gil-Martín E and Fernández-Briera A: Synthesis and expression of CDw75 antigen in human colorectal cancer. BMC Cancer 9: 431, 2009.

23. Villar-Portela S, Muinelo-Romay L, Cuevas E, Gil-Martín E and Fernández-Briera A: Disease-free survival of colorectal cancer patients in relation to CDw75 antigen expression. Pathobiology 78: 201-209, 2011.

24. Lopez LC, Maillet CM, Oleszkowicz K and Shur BD: Cell surface and Golgi pools of beta-1,4-galactosyltransferase are differentially regulated during embryonal carcinoma cell differentiation. Mol Cell Biol 9: 2370-2377, 1989.

25. Smets LA and Van Beek WP: Carbohydrates of the tumour cell surface. Biochim Biophys Acta 738: 237-249, 1984.

26. Ramagli LS and Rodriguez L: Quantitation of microgram amounts of protein in two-dimensional polyacrylamide ge electrophoresis sample buffer. Electrophoresis 6: 559-563, 1985.

27. Rappsilber J, Ryder U, Lamond AI and Mann M: Large-scale proteomic analysis of the human spliceosome. Genome Res 12 1231-1245, 2002.

28. Zhang $X$ and Zheng PS: Expression and significance of CK7 and CK19 in colon cancer. Xi Bao Yu Fen Zi Mian Yi Xue Za Zhi 26 157-158, 2010 (In Chinese).

29. Wu C, Jin X, Tsueng G, Afrasiabi C and Su AI: BioGPS: Building your own mash-up of gene annotations and expression profiles. Nucl Acids Res 44: D313-D316, 2016.

30. DiGiacomo V and Meruelo D: Looking into laminin receptor: Critical discussion regarding the non-integrin 37/67-kDa laminin receptor/RPSA protein. Biol Rev Camb Philos Soc 91: 288-310, 2016.

31. Chang YJ, Chen WY, Huang CY, Liu HH and Wei PL: Glucose-regulated protein 78 (GRP78) regulates colon cancer metastasis through EMT biomarkers and the NRF-2/HO-1 pathway. Tumor Biol 36: 1859-1869, 2015.

32. Black JD and Rezvani K: Heat shock protein 70 s as potential molecular targets for colon cancer therapeutics. Curr Med Chem 23: 3171-3188, 2016.

33. Chang Y, Wu Y, Liu W and Ji G: Knockdown of ERp44 leads to apoptosis via activation of ER stress in HeLa cells. Biochem Biophys Res Commun 463: 606-611, 2015.

34. Weber J and Senior AE: ATP synthesis driven by proton transport in F1F0-ATP synthase. FEBS Lett 545: 61-70, 2003.

35. Mitchell P: Protonmotive redox mechanism of the cytochrome b-cl complex in the respiratory chain: Protonmotive ubiquinone cycle. FEBS Lett 56: 1-6, 1975.

36. Hong S and Pedersen PL: ATP synthase and the actions of inhibitors utilized to study its roles in human health, disease, and other scientific areas. Microbiol Mol Biol Rev 72: 590-641, 2008.

37. Xia D, Esser L, Tang WK, Zhou F, Zhou Y, Yu L and Yu CA: Structural analysis of cytochrome bcl complexes: Implications to the mechanism of function. Biochim Biophys Acta 1827: 1278-1294, 2013

38. Moll R, Divo M and Langbein L: The human keratins: Biology and pathology. Histochem Cell Biol 129: 705-733, 2008.

39. Fuchs E and Cleveland DW: A structural scaffolding of intermediate filaments in health and disease. Science 279: 514-519, 1998

40. Chou CF, Smith AJ and Omary MB: Characterization and dynamics of O-linked glycosylation of human cytokeratin 8 and 18. J Biol Chem 267: 3901-3906, 1992.

41. Giblett ER: The haptoglobin system. Ser Haematol 1: 3-2012, 1968.

42. Uhlén M, Björling E, Agaton C, Szigyarto CA, Amini B, Andersen E, Andersson AC, Angelidou P, Asplund A, Asplund C, et al: A human protein atlas for normal and cancer tissues based on antibody proteomics. Mol Cell Proteomics 4: 1920-1932, 2005.
43. Harvey S, Kohga S, Sait SN, Markus G, Hurd TC, Martinick M, Geradts J, Saxena R and Gibbs JF: Co-expression of urokinase with haptoglobin in human carcinomas. J Surg Res 152: 189-197, 2009.

44. Nakano M, Nakagawa T, Ito T, Kitada T, Hijoka T, Kasahara A, Tajiri M, Wada Y, Taniguchi N and Miyoshi E: Site-specific analysis of $\mathrm{N}$-glycans on haptoglobin in sera of patients with pancreatic cancer: A novel approach for the development of tumor markers. Int J Cancer 122: 2301-2309, 2008.

45. Okuyama N, Ide Y, Nakano M, Nakagawa T, Yamanaka K, Moriwaki K, Murata K, Ohigashi H, Yokoyama S, Eguchi H, et al: Fucosylated haptoglobin is a novel marker for pancreatic cancer: A detailed analysis of the oligosaccharide structure and a possible mechanism for fucosylation. Int J Cancer 118: 2803-2808, 2006.

46. Park SY, Yoon SJ, Jeong YT, Kim JM, Kim JY, Bernert B, Ullman T, Itzkowitz $\mathrm{SH}, \mathrm{Kim} \mathrm{JH}$ and Hakomori SI: $\mathrm{N}$-glycosylation status of beta-haptoglobin in sera of patients with colon cancer, chronic inflammatory diseases and normal subjects. Int J Cancer 126: 142-155, 2010.

47. Majumdar D, Tiernan JP, Lobo AJ, Evans CA and Corfe BM Keratins in colorectal epithelial function and disease. Int J Exp Pathol 93: 305-318, 2012.

48. Modjtahedi N, Frebourg T, Fossar N, Lavialle C, Cremisi C and Brison O: Increased expression of cytokeratin and ferritin- $\mathrm{H}$ genes in tumorigenic clones of the SW 613-S human colon carcinoma cell line. Exp Cell Res 201: 74-82, 1992.

49. Mouat MF, Kolli K, Orlando R, Hargrove JL and Grider A: The effects of quercetin on SW480 human colon carcinoma cells: A proteomic study. Nutr J 4: 11, 2005.

50. Knösel T, Emde V, Schlüns K, Schlag PM, Dietel M and Petersen I: Cytokeratin profiles identify diagnostic signatures in colorectal cancer using multiplex analysis of tissue microarrays. Cell Oncol 28: 167-175, 2006.

51. Polley AC, Mulholland F, Pin C, Williams EA, Bradburn DM, Mills SJ, Mathers JC and Johnson IT: Proteomic analysis reveals field-wide changes in protein expression in the morphologically normal mucosa of patients with colorectal neoplasia. Cancer Res 66: 6553-6562, 2006.

52. Koelink PJ, Sier CF, Hommes DW, Lamers CB and Verspaget HW: Clinical significance of stromal apoptosis in colorectal cancer. $\mathrm{Br}$ J Cancer 101: 765-773, 2009.

53. Godfroid E, Geuskens M, Dupressoir T, Parent I and Szpirer C: Cytokeratins are exposed on the outer surface of established human mammary carcinoma cells. J Cell Sci 99: 595-607, 1991.

54. Wells MJ, Hatton MW, Hewlett B, Podor TJ, Sheffield WP and Blajchman MA: Cytokeratin 18 is expressed on the hepatocyte plasma membrane surface and interacts with thrombin-antithrombin complexes. J Biol Chem 272: 28574-28581, 1997.

55. Gires O, Andratschke M, Schmitt B, Mack B and Schaffrik M: Cytokeratin 8 associates with the external leaflet of plasma membranes in tumor cells. Biochem Biophys Res Commun 328: 1154-1162, 2005.

56. Hart GW, Haltiwanger RS, Holt GD and Kelly WG: Glycosylation in the nucleus and cytoplasm. Annu Rev Biochem 58: 841-874, 1989.

57. Greis KD and Hart GW: Nuclear and cytoplasmic glycoproteins. In: Glycoproteins II. Montreuil J, Vliegenthart JFG and Schachter H (eds.) Elsevier Science, Amsterdam, pp33-51, 1997.

58. Lee HS, Qi Y and Im W: Effects of N-glycosylation on protein conformation and dynamics: Protein Data Bank analysis and molecular dynamics simulation study. Sci Rep 5: 8926, 2015. 